\title{
Effects of UV-C Light Exposure and Refrigeration on Phenolic and Antioxidant Profiles of Subtropical Fruits (Litchi, Longan, and Rambutan) in Different Fruit Forms
}

\author{
Peilong Li, Xiaoming Yu, and Baojun Xu \\ Food Science and Technology Program, Beijing Normal University-Hong Kong Baptist University United International College, \\ Zhuhai, Guangdong 519085, China \\ Correspondence should be addressed to Baojun Xu; baojunxu@uic.edu.hk
}

Received 23 June 2017; Revised 17 October 2017; Accepted 12 November 2017; Published 14 December 2017

Academic Editor: Sunil Pareek

Copyright (c) 2017 Peilong Li et al. This is an open access article distributed under the Creative Commons Attribution License, which permits unrestricted use, distribution, and reproduction in any medium, provided the original work is properly cited.

\begin{abstract}
The objectives of this study were to investigate how UV-C irradiation and refrigeration affect shelf-life and antioxidant level of litchi, longan, and rambutan. Three forms (whole, dehulled, and destoned) of fresh fruits were treated by refrigeration and UV-C irradiations. After processing, deterioration rate, phenolics compounds, and antioxidant capacity were quantified. The deterioration rate was recorded as decay index. The results showed that both refrigeration and UV-C exposure extended the shelf-life of the fruits. The refrigeration enriched antioxidant levels of litchi but caused nutritional degradation in longan and rambutan; UV-C radiation enriched litchi antioxidant contents but was related to reduction of antioxidant capacity in longan and rambutan. Removing hulls and stones was associated with the decrease of antioxidants in litchi. The effects on antioxidant levels varied from fruit to fruit, resulting from hormesis phenomenon. The change of phytochemical levels was hypothesized as an accumulative process. The effects of fruit forms were not consistent in different fruits, which could be multifactorially influenced.
\end{abstract}

\section{Introduction}

An epidemiological study revealed that human body can benefit from consumption of five servings ( $400 \mathrm{~g}$ in total) of fruits and vegetables per day, which potentially decreases the vulnerability to chronic noncommunicable diseases, like colon cancer, stroke, and arteriosclerosis [1]. To a great extent, merits brought by fruits can be attributed to phytochemical composition, especially antioxidants, including phenolic derivatives like polyphenols and flavonoids [2]. $L$-ascorbic acid, the heat-labile vitamin $\mathrm{C}$ with recommended dietary allowance of $90 \mathrm{mg} /$ day for males and $75 \mathrm{mg} /$ day for females [3], can be also largely obtained from fruits. Antioxidants can help to neutralize reactive oxygen species generated in human body, consequently reducing tissue damage and alleviating oxidative stress [4].

Longan (Dimocarpus longan Lour.), litchi (Litchi chinensis Sonn.), and rambutan (Nephelium lappaceum L.) are typical subtropical fruits opulently cultivated in southern China, which are popular for customer to buy in summer (from June to August). However, due to cell-membrane lipid peroxidation and polyphenol oxidation [5], the inherent perishability of these fruits has been considered as a serious problem, leading to fruit browning or fungal infection in the first week after being harvested from orchard, which greatly impairs economic chain of fruit agriculture [6]. Consequently, perishable fruits are being investigated by researchers for extending their shelf-life [7]. Diluted chlorine is an approach for sanitization of fresh fruit in industry, which is commercially feasible considering cost-effectiveness ratio. However, chlorine has been hypothesized as a source of carcinogenic chlorinated chemicals [8], which thus urges industry to find other alternatives.

Ultraviolet radiation is commonly applied in food industry, including fruit postharvest processing, which barely has adverse impact on original flavor and texture, greatly ensuring the food quality compared with conventional blanching [9]. Ultraviolet (100 to $400 \mathrm{~nm}$ ), the high-frequency electromagnetic waves, can extend the shelf-life by stress-induced 
defense responses that reduce infection and cellular damage [10-12], and it has been the object of a number of research works. For instance, Erkan et al. [13] indicated that 5 and 10 min UV-C illumination $\left(0.43,2.15\right.$, and $\left.4.30 \mathrm{~kJ} \mathrm{~m}^{-2}\right)$ provided the best decay suppression on strawberries; PerkinsVeazie et al. [14] found $1-4 \mathrm{~kJ} \mathrm{~m}^{-2}$ UV-C light exposure reduced $10 \%$ of decay incidence from ripe rot. Numerous studies showed UV treatment can stimulate synthesis of phytoalexin which are antimicrobial compounds contributing in disease resistance $[15,16]$. More important, both UV-B (280-315 nm) and UV-C (100-280 nm) treatments have been reported that can enrich certain nutrients and nutraceutical compounds [12, 17]. Favory et al. [18] revealed that UV-B radiation stimulated COP1 and UVR8 photoperception protein, enhancing accumulation of anti-ultraviolet molecules. Luthria et al. [19] pointed out that phenolic contents in tomato were enriched due to solar UV-B exposure (290 to $400 \mathrm{~nm}$ ), especially caffeic acid. Castagna et al. [20] agreed that UV-B treatment $\left(1 \mathrm{~h}, 6.08 \mathrm{~kJ} \mathrm{~m}^{-2} \mathrm{~d}\right)$ enriched $L$-ascorbic acid as well as carotenoids in Monkey marker tomato. Alothman et al. [21] indicated that UV-C irradiation $\left(2.158 \mathrm{~kJ} \mathrm{~m}^{-2}\right)$ elevated levels of phenolic and flavonoid contents of guava and banana; cisas well as trans-piceid in table grape was tripled after UV-C exposure [22].

Refrigeration is also an important postharvest procedure for fruits, which contributes to inactivation of polyphenol oxidase and inhibition of microbial growth, as well as decrease of membrane leakage, and thus can prolong shelf-life [5, 23]. Additionally, Crupi et al. [22] bridged UV-C exposure with storage time and investigated the effects of treatments on table grape and found that after being stored for $24 \mathrm{~h}$, level of cyanidin-3-O-glucoside peaked. This phenomenon was attributed to defense response stimulated by UV-C light $\left(0.8,2.4\right.$, and $\left.4.1 \mathrm{~kJ} \mathrm{~m}^{-2}\right)$, which triggered transcription of mRNA afterward. It would also be meaningful to understand whether antioxidant levels of litchi, longan, and rambutan are altered immediately after UV treatment or, gradually, controlled by gene expression.

Litchi, longan, and rambutan have similar structure: outer hull (exocarp) protects edible pulp (mesocarp) containing internal core stone (endocarp and seed) [24]. In processing value-added product, like fruit beverage or dried fruit, industry always removes nonedible parts (hull and stone) in intermediate step. So far, no research was published in the effect of dehulling and destoning on fruit antioxidant profile during UV treatment. Understanding how fruit forms contribute to the changes of antioxidant components would be meaningful in value-added product processing.

This study aimed to investigate the effects of UV-C radiation and refrigeration on antioxidant profiles of litchi, longan, and rambutan, as well as the effects of fruit forms (dehulled and destoned), on the changes of nutritional level induced by $\mathrm{UV}-\mathrm{C}$ treatment and refrigerated storage.

\section{Materials and Methods}

2.1. Fruit Samples. The experiments were conducted in summer in 2016: litchi in June, longan in July, and rambutan in August. Litchi (Litchi chinensis Sonn. cv. Feizixiao) was freshly harvested from an orchard in Zhuhai, China. Longan (Dimocarpus longan Lour. cv. Shixia) was collected from farm in Guangzhou, China. Rambutan (Nephelium lappaceum L.) was collected from farm in Sanya, China. Before treatments, fruits were debranched and sorted to remove damaged samples. Sorted samples were divided into $300 \mathrm{~g}$ for each group. In each group, one-third fruits were dehulled; one-third fruits were destoned; the rest of one-third remained in whole fruit. Removing hulls and stones were carefully conducted to minimize juice leakage.

2.2. Chemicals and Reagents. (+)-Catechin was obtained from Sigma Chemical Co. (St. Louis, MO, USA). Sodium hydroxide, citric acid, $L$-ascorbic acid, metaphosphoric acid, gallic acid, sodium nitrite, aluminum chloride, sodium acetate, and ferrous sulphate were purchased from Damao Chemical Co. (Tianjin, China). Folin-Ciocalteu working solution, 2,6-dichlorophenolindophenol (DCIP), 2-diphenyl-1-picrylhydrazyl (DPPH), 6-hydroxy-2,5,7,8-tetramethylchroman-2-carboxylic acid (Trolox), 2,4,6-tri(2-pyridyl)-striazine (TPTZ), and 2,2' -azino-bis(3-ethylbenzothiazoline6-sulphonic acid) (ABTS) were provided by Yuanye Biotechnical Company (Shanghai, China). Acetic acid, hydrochloric acid, and acetone were obtained from Guangzhou Chemical Reagent Factory (Guangzhou, Guangdong, China). Ferric chloride was purchased from Sinopharm Chemical Reagent (Shanghai, China). Ethanol was supplied by Fuyu Fine Chemical Co. (Tianjin, China). All reagents used were of analytical grade.

2.3. UV-C Light Treatment and Refrigeration. Sample preparation of each group was described in Table 1. Group A samples were refrigerated at $4^{\circ} \mathrm{C}$ in dark (humidity: $45 \% \pm$ $3 \%$ ) for $24 \mathrm{~h}$; Group B were stored in $4^{\circ} \mathrm{C}$ for $24 \mathrm{~h}$ and then treated by UV-C light $(254 \mathrm{~nm})$ using UV Crosslinker (CL1000, Ultra-Violet Products Ltd., UK) with preset UV energy mode (dose: $3 \mathrm{~kJ} \mathrm{~m}^{-2}$ ); Group $\mathrm{C}$ were irradiated by UV-C light $\left(3 \mathrm{~kJ} \mathrm{~m}^{-2}\right)$ first and then stored at $4^{\circ} \mathrm{C}$ for $24 \mathrm{~h}$; Group $\mathrm{N}$, as control group, were not treated by refrigeration or UV$\mathrm{C}$ irradiation. During storage, dehulled and destoned fruits were kept in clean glassware sealed by plastic film to reduce moisture loss. During UV-C exposure, $150 \mathrm{~g}$ of fruits (15 litchis, or 15 longans, or 10 rambutans) was treated as a batch; fruit stalk was horizontally oriented.

2.4. Determination of Moisture Content. After treatments, all treated samples were ground into homogenous pulp juice (without hull and stone). Grinder (Philips Co., HR2006, Zhuhai) was washed twice by approximately $50 \mathrm{~mL}$ distilled water for reducing sample loss. Homogenized samples were collected in clean, sealed glass bottles and stored in dark at $4^{\circ} \mathrm{C}$ for further using. Moisture of juice was measured according to National Standard of China [25]. Empty clean aluminum containers were preweighted, recorded as $m_{0}$. Approximately $5 \mathrm{~g}$ of sample was transferred into each container, with exact weight record as $m_{1}$. All open aluminum containers were placed in vacuum oven (Memmert Co., VO200, Shanghai) at $T=70^{\circ} \mathrm{C}$ and $P=3 \mathrm{kPa}$ for $4 \mathrm{~h}$. Dry 
TABLE 1: Group and subgroup codes with corresponding description.

\begin{tabular}{|c|c|c|}
\hline \multicolumn{2}{|c|}{ Code combinations } & \multirow{2}{*}{ Descriptions } \\
\hline Treatments & Fruit forms & \\
\hline \multirow{3}{*}{$\mathrm{N}$} & 1 & Whole fruits in control group \\
\hline & 2 & Dehulled fruits in control group \\
\hline & 3 & Destoned fruits in control group \\
\hline \multirow{3}{*}{$\mathrm{A}$} & 1 & Whole fruits in solely refrigerated group \\
\hline & 2 & Dehulled fruits in solely refrigerated group \\
\hline & 3 & Destoned fruits in solely refrigerated group \\
\hline \multirow{3}{*}{ B } & 1 & Whole fruits refrigerated in dark and then irradiated by UV-C light \\
\hline & 2 & Dehulled fruits refrigerated in dark and then irradiated by UV-C light \\
\hline & 3 & Destoned fruits refrigerated in dark and then irradiated by UV-C light \\
\hline \multirow{3}{*}{$\mathrm{C}$} & 1 & Whole fruits irradiated by UV-C light and then refrigerated in dark \\
\hline & 2 & Dehulled fruits irradiated by UV-C light and then refrigerated in dark \\
\hline & 3 & Destoned fruits irradiated by UV-C light and then refrigerated in dark \\
\hline
\end{tabular}

weight, when it is constant, was recorded as $\mathrm{m}_{2}$. The moisture content was calculated as $\left(m_{1}-m_{2}\right) /\left(m_{1}-m_{0}\right) \times 100 \%$. Moisture determination was conducted in triplicate.

2.5. Extraction of Phenolic Compounds and Antioxidants from Fruit. Extractions for determination of TPC, TFC, DPPH scavenging capacity, ferric reducing antioxidant power, and ABTS radical scavenging capacity were conducted based on the established method [26]. Approximately $5 \mathrm{~g}$ of homogenized pulp (exact sample weight was recorded) was added in centrifugal tube with $5 \mathrm{~mL}$ of acetic acetone (acetone: water: acetic acid $=70: 29.5: 0.5, \mathrm{v} / \mathrm{v} / \mathrm{v})$. The mixture was shaken for $3 \mathrm{~h}$ on an orbital shaker and then was set stilly in dark for $12 \mathrm{~h}$. Mixture was centrifuged at $5000 \mathrm{rpm}$ for $10 \mathrm{~min}$ to collect extract. The above extraction step was performed twice and supernatant was combined with final volume recorded.

$L$-ascorbic acid was extracted based on the method previously reported by Reiss [27]. Approximately $25 \mathrm{~g}$ of homogenized pulp (exact sample weight was recorded) was added in grinder with $100 \mathrm{~mL}$ of $3 \%$ metaphosphoric acid. Mixture was homogenized at high speed for $2 \mathrm{~min}$ and then was filtered. The supernatant was collected and the volume was recorded. Extractions were conducted in triplicate for each combination between treatments and fruit forms.

2.6. Determination of L-Ascorbic Acid. The determination of $L$-ascorbic acid was based on DCIP colorimetric method [28]. The content of $L$-ascorbic acid was calculated through equation $y=-39.482 x+0.5054$ calibrated by $L$-ascorbic acid. Standard curve had a linear range from 0 to $10 \mathrm{mg} \mathrm{L}^{-1}$ and correlation coefficient $=0.9996$. Results were expressed in dry weight basis.

2.7. Determination of Total Phenolic Content (TPC). TPC was determined with Folin-Ciocalteu method reported by Singleton et al. [29]. The total phenolic content was calculated as gallic acid equivalents ( $\left.\mathrm{g} \mathrm{GAE} \mathrm{kg}^{-1}\right)$. Gallic acid calibration curve $(y=0.0012 x+0.0068)$ ranged from 10 to $500 \mathrm{mg} \mathrm{L}^{-1}$ $\left(r^{2}=0.9998\right)$. Results were recorded in dry weight basis.
2.8. Determination of Total Flavonoid Content (TFC). Determination of TFC was conducted using aluminum chloride colorimetric method which has been established previously [30]. The result of TFC was calculated by (+)-catechincalibrated standard curve ranging from 10 to $1000 \mathrm{mg} \mathrm{L}^{-1}$ with correlation coefficient $=0.9996$ and was expressed as catechin equivalents ( $\mathrm{g} \mathrm{CE} \mathrm{kg}^{-1}$ ) in dry weight basis.

2.9. Determination of DPPH Free Radical Scavenging Capacity. DPPH free radical scavenging assay was conducted according to previous literature [31]. The scavenging rate was calculated as $\left(A_{\text {control }}-A_{\text {sample }}\right) / A_{\text {control }} \times 100 \%$. Scavenging capacity was calculated by applying sample scavenging rate to Troloxcalibrated curve: $y=0.0012 x-0.0037, R^{2}=0.9905(0.1 \sim$ $1 \mathrm{mM}$ ). Results were expressed as Trolox equivalents (mol TE $\mathrm{kg}^{-1}$ ) in dry weight basis.

2.10. Determination of Ferric Reducing Antioxidant Power. Ferric reducing antioxidant power was evaluated based on the method established previously [32]. FRAP was calculated by regression equation $\left(y=0.639 x-0.0239, R^{2}=0.995\right)$ calibrated by ferrous sulphate from 0.1 to $1 \mathrm{mM}$. Ferric reducing antioxidant power was expressed as $\mathrm{Fe}^{2+}$ equivalents (mmol $\mathrm{FE} \mathrm{kg}^{-1}$ ) in dry weight basis.

2.11. Determination of ABTS Free Radical Scavenging Capacity. ABTS radical scavenging assay was conducted based on the method established previously [33]. The inhibitory rate was calculated as $\left(A_{\text {control }}-A_{\text {sample }}\right) / A_{\text {control }} \times 100 \%$. Scavenging power was expressed as Trolox equivalents, computed through standard curve with range from 0 to $100 \mathrm{mM}$. Results were expressed as Trolox equivalents $\left(\mathrm{g} \mathrm{TE} \mathrm{kg}^{-1}\right)$ in dry weight basis.

2.12. Determination of Decay Index. The determination of decay index was illustrated previously [34]. Processed whole fruits were grouped (litchi and longan: 10 fruits for a batch; rambutan: 5 fruits for a batch). The decay areas (color change due to skin browning or fungal growth) were visually observed and recorded, which were categorized as follows: 
level 0 (normal appearance), level 1 (decay proportion $\leq 0.25$ ), level $2(0.25<$ decay proportion $\leq 0.5)$, level $3(0.5<$ decay proportion $\leq 0.75)$, level $4(0.75<$ decay proportion $\leq 1)$, and level 5 (decay proportion $=1$ ). The overall average decay index of each group was calculated with $\Sigma$ (decay level $\times$ numbers of fruits in this level)/fruits number of each group. Determination of decay index was done in triplicate and results were averaged.

2.13. Statistical Analysis. All the above assays were conducted in triplicate from extraction step, and results were expressed as mean \pm standard deviation in dry weight basis. The data were analyzed by one-way ANOVA using SPSS (Version 19, IBM Co., USA). Duncan's multiple comparison was applied in order to figure out whether significant differences exist among phytochemical levels of different treatments and fruit forms with $p$ value $\leq 0.05$. Two-way ANOVA was also applied to test the interaction between treatments and fruit forms at 0.05 significant levels. Correlation matrix of tested parameters was constructed in scatter plot with Pearson correlation coefficients noted.

\section{Results}

3.1. Effects of UV-C Radiation and Refrigeration on Decay Rate. The decay proliferations of litchi, longan, and rambutan, expressed as decay index, were illustrated in Figure 1. Basically, ordinary untreated litchi and longan started to brown in the second day after being harvested from tree, and rambutan even underwent darkening from the first day. In terms of fruit species, rambutan showed the fastest rate of decaying, which has been entirely darkened with decay index just slightly lower than 5.0 on day 7. On the contrary, litchi performs better in storage property, with fairly slow initial deterioration speed, reaching only 1.0 decay index in the 5 th day.

Compared with control group $(\mathrm{N})$, fruits either cold refrigerated or treated by UV-C light apparently had longer shelf-life, indicating that UV-C treatment and refrigeration both can delay deterioration rate. Additionally, compared with fruit treated by sole refrigeration (A), fruits irradiated by UV-C light (groups B and C) performed better in inhibiting decay rate. However, the results of fruits irradiated by UV$\mathrm{C}$ light before and after 24-hour cold storage did not show significant gap in decay index: line chart of groups B and C cannot clearly be separated with each other.

3.2. Antioxidant Profiles of Fruits in Different Forms upon Different Treatments. Table 2 shows the results of antioxidant profile of litchi, longan, and rambutan treated differently. In each group, fruits were categorized by distinct fruit forms: whole fruits, dehulled fruits, and destoned fruits, respectively. Table 3 showed the result of two-way ANOVA $(p \leq 0.05)$ for testing whether there was any interaction between treatments (UV-C radiation and refrigeration) and fruit forms (whole, dehulled, and destoned).

Generally, longan contained higher $L$-ascorbic acid content (ranging from 1.60 to $2.24 \mathrm{~g} \mathrm{~kg}^{-1}$ ) than the counterpart of litchi (data of rambutan's $L$-ascorbic acid content was not available). However, litchi performed stronger in TPC (ranging from 3.83 to $5.19 \mathrm{~g} \mathrm{~kg}^{-1}$ ), TFC (from 1.23 to $1.68 \mathrm{~g} \mathrm{~kg}^{-1}$ ), FRAP (from 31.61 to $38.27 \mathrm{mmol} \mathrm{kg}^{-1}$ ), and ABTS free radical scavenging capacity (from 1.31 to $1.67 \mathrm{~mol} \mathrm{~kg}^{-1}$ ). DPPH free radical scavenging capacity was higher in longan (from 8.80 to $12.26 \mathrm{~mol} \mathrm{~kg}^{-1}$ ). Rambutan showed the weakest antioxidant capacity.

According to the correlation matrix in Figure 2, Lascorbic acid did not show a clear relationship with most of tested parameters. On the contrary, the rest of paired scatter plots all showed statistically significant positive correlations except the pair between TFC and DPPH free radical scavenging capacity in litchi, and the pair between TPC and ABTS free radical scavenging capacity in longan. TPC strongly correlated with DPPH free radical scavenging capacity $\left(r^{2}=\right.$ $0.845)$ as well as ABTS free radical scavenging capacity $\left(r^{2}=\right.$ 0.818 ) in litchi and was closely associated with DPPH free radical scavenging capacity $\left(r^{2}=0.847\right)$ in longan. It should be noticed that three assays of antioxidant capacity in rambutan closely related to each other with all correlation coefficients above 0.84 ( 0.843 between DPPH free radical scavenging capacity and FRAP, 0.928 between DPPH free radical and ABTS free radical scavenging capacity, and 0.850 between FRAP and ABTS free radical scavenging capacity).

3.2.1. Effects of UV-C Treatment and Refrigeration on Litchi. The change of levels of $L$-ascorbic acid, TPC, TFC, DPPH free radical scavenging capacity, FRAP, and ABTS free radical scavenging capacity in whole litchi fruit is illustrated in Figure 3(a). For each parameter, different subscripts note the existence of significant difference. Comparing solely refrigerated whole litchi fruit with control group, refrigeration enriched levels of TPC, TFC, DPPH free radical scavenging capacity, FRAP, and ABTS free radical scavenging capacity. Additionally, fruits which were irradiated by ultraviolet (Groups B1 and $\mathrm{Cl}$ ), compared with solely refrigerated whole fruits, had further increase in $L$-ascorbic acid, TFC, and DPPH free radical scavenging power. The values of TPC, FRAP, and ABTS free radical scavenging capacity were also higher after UV-C treatment, though not significant. The treatment sequence was also associated with the distinguishable disparities of phytochemical levels: litchis that experienced UV-C radiation before storage showed higher $L$ ascorbic acid content, whereas litchis treated by UV-C treatment after storage performed stronger in DPPH free radical scavenging capacity. The remaining parameters did not show significant gaps between fruits in these two treatments.

\subsubsection{Effects of Dehulling and Destoning on Litchi's Antioxidant} Profile. Levels of $L$-ascorbic acid, TPC, TFC, DPPH free radical scavenging capacity, FRAP, and ABTS free radical scavenging capacity in litchis with different fruit forms (whole, dehulled, and destoned) are illustrated in Table 2. In Group A (only refrigerated), compared with whole fruit, dehulled litchis contained higher level of $L$-ascorbic acid content, TFC, and DPPH free radical scavenging capacity; litchis without inner core stone performed stronger in $L$-ascorbic acid, TPC, TFC, and DPPH free radical and ABTS free 







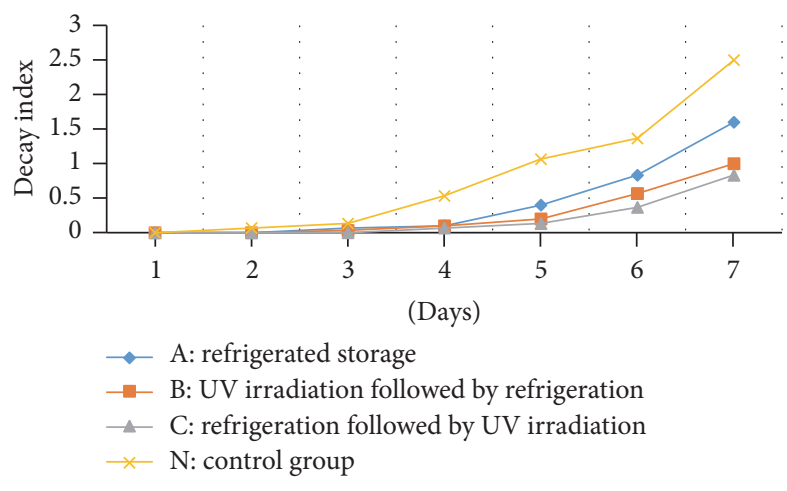

(a)

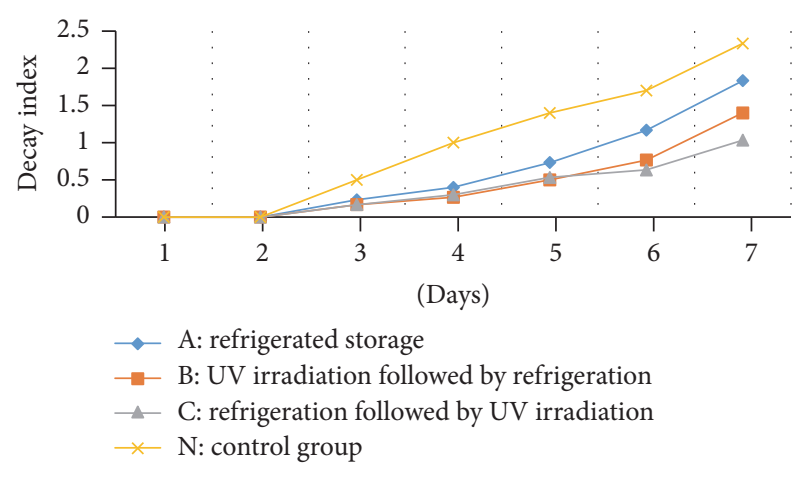

(b)

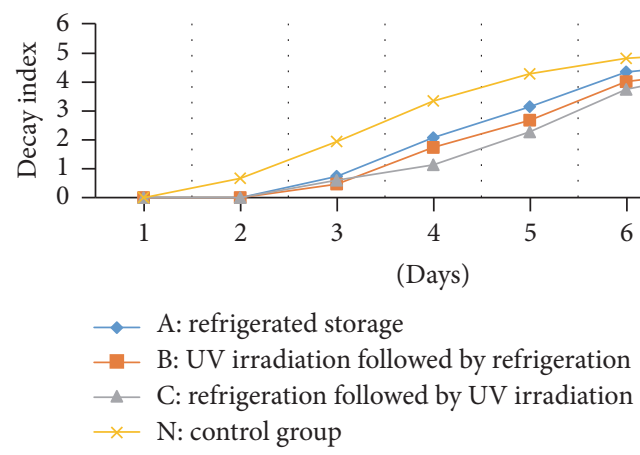

(c)

FIGURE 1: Decay proliferation of litchis (a), longans (b), and rambutans (c) during first week after treatments.

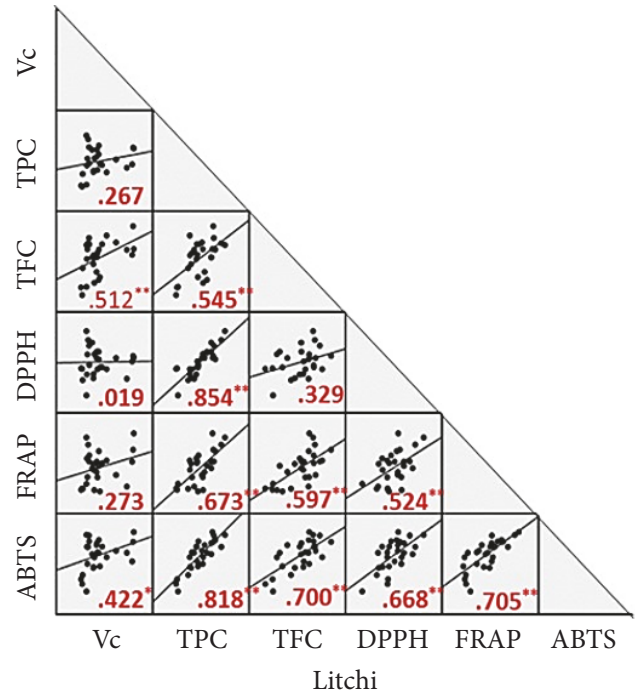

${ }^{*}$ Correlation is significant at 0.05 level (2-tailed).

** Correlation is significant at 0.01 level (2-tailed).
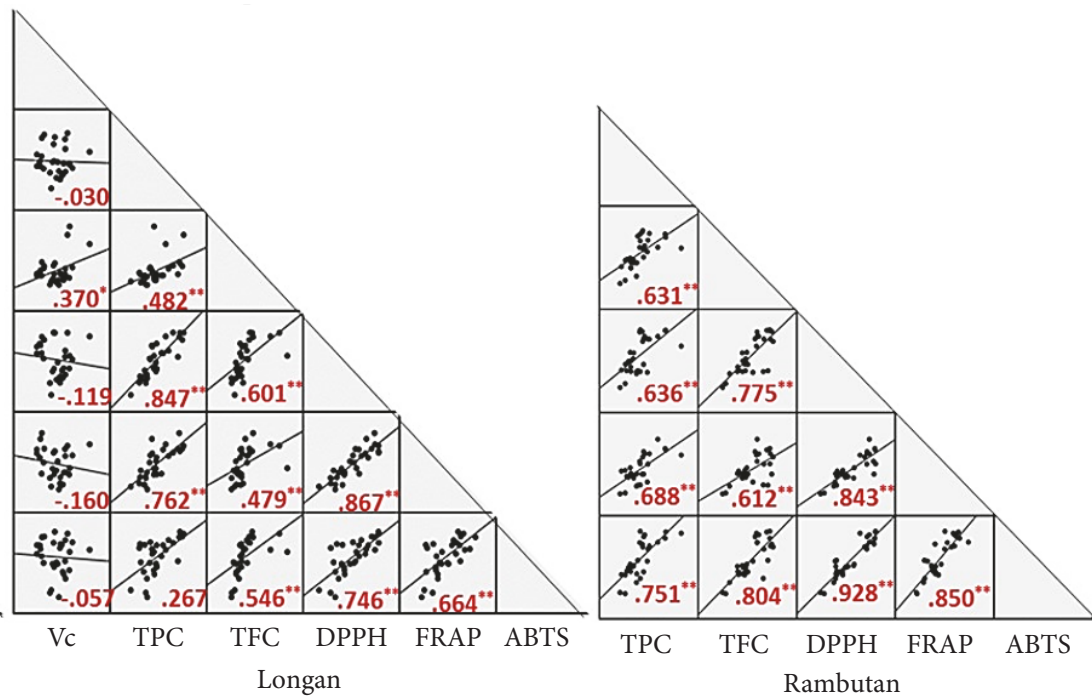

FIGURE 2: Correlation matrix of phytochemical parameters ( $L$-ascorbic acid, TPC, TFC, FRAP, DPPH free radical, and ABTS free radical scavenging capacity) of litchi, longan, and rambutan.

radical scavenging capacities. According to results obtained from the litchi group irradiated by UV-C after cold storage, although whole litchis fruit in this group experienced sharp increases in all phytochemicals determined compared with control, peeling and destoning weakened this increase, and, in particular, $L$-ascorbic acid, which was even lower than the level in whole litchi fruit, and these tendencies were not found in solely refrigerated group. Based on two-way ANOVA (Table 3), interaction between treatments and fruit forms was significant, showing $L$-ascorbic acid content, TPC, 

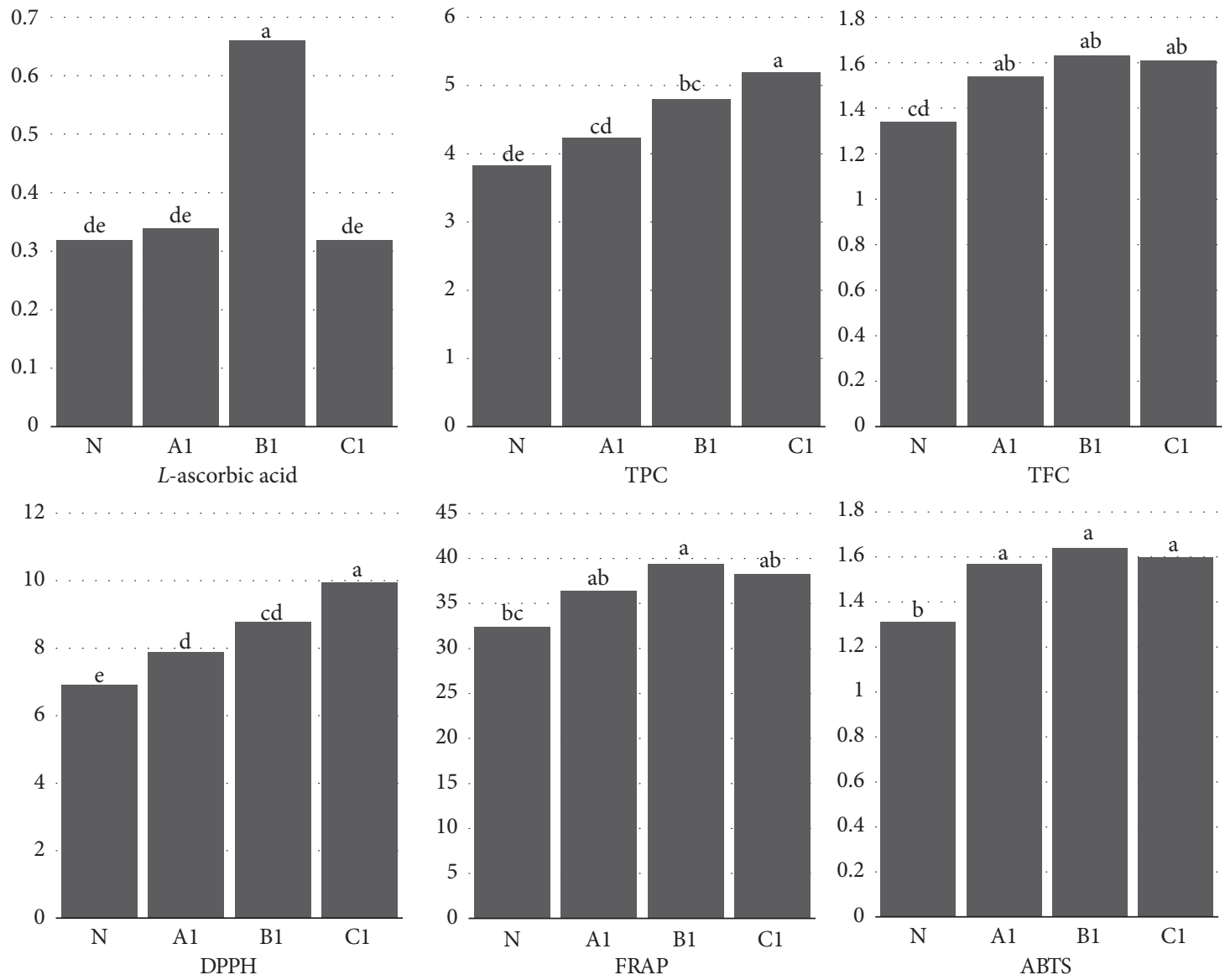

(a)
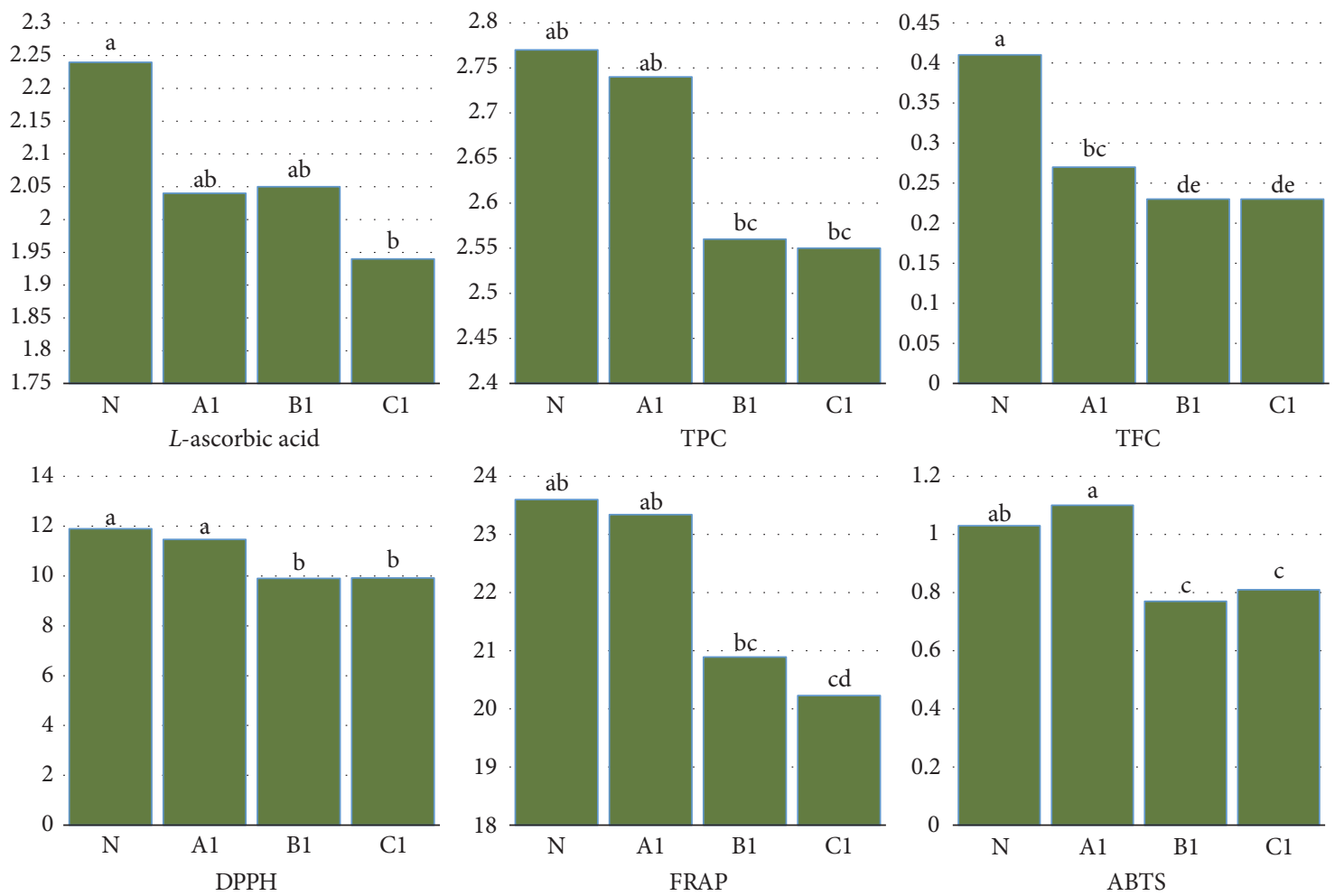

(b)

FIgUre 3: Continued. 

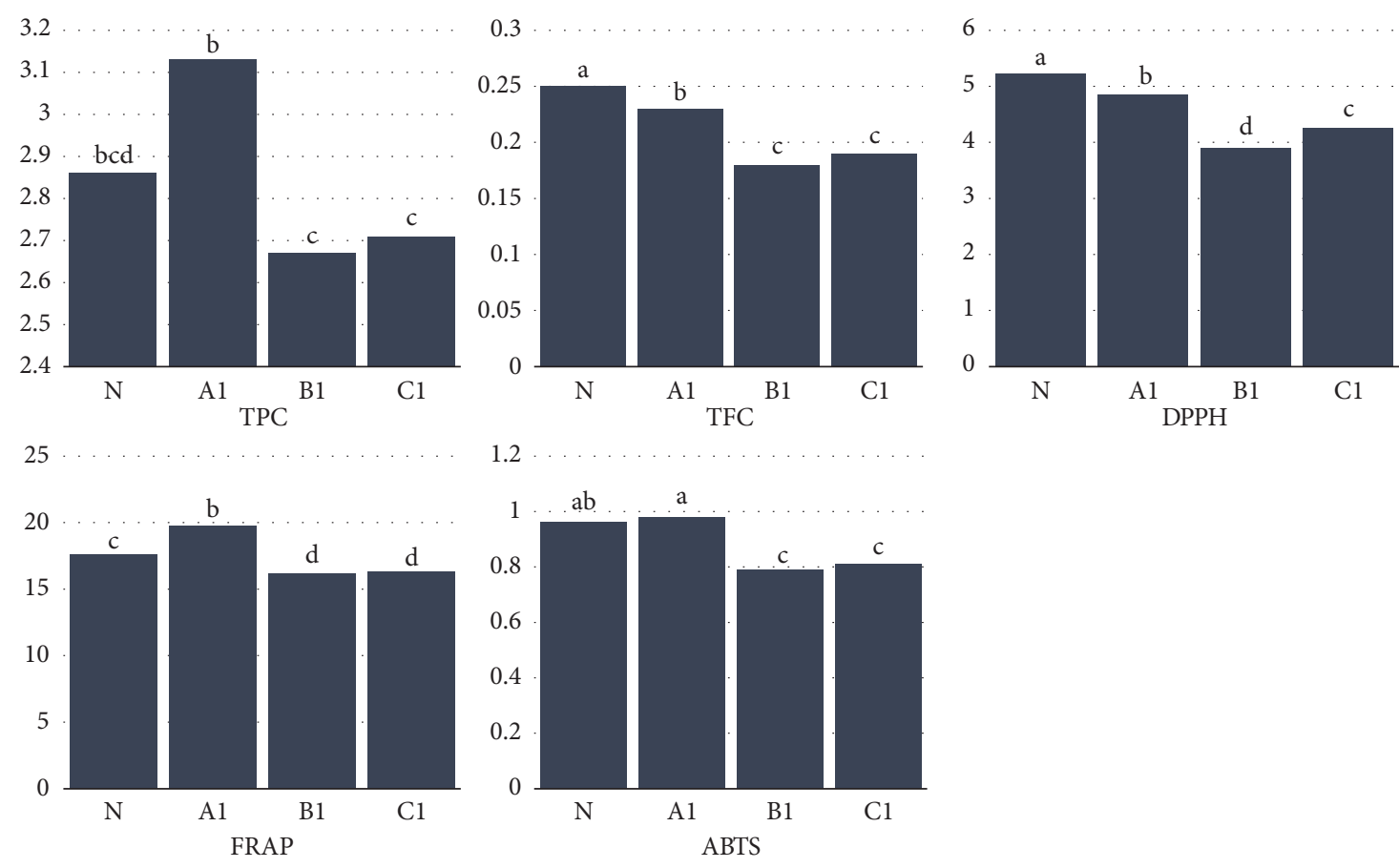

(c)

FIGURE 3: Levels of $L$-ascorbic acid, TPC, TFC, DPPH free radical scavenging capacity, FRAP, and ABTS free radical scavenging capacity in whole litchi fruit (a), longan (b), and rambutan (c) after different pretreatments: refrigeration (A), refrigeration-UV (B), UV-refrigeration, (C) and control $(\mathrm{N})$.

TABLE 3: $p$ value of interaction between treatments and fruit forms shown in examined parameters in litchi, longan, and rambutan tested by two-way ANOVA.

\begin{tabular}{lccccccc}
\hline & Fruits & $L$-ascorbic acid & TPC & TFC & DPPH & FRAP & ABTS \\
\hline \multirow{3}{*}{$p$ value of interaction } & Litchi & $0.001^{*}$ & $0.004^{*}$ & $0.004^{*}$ & 0.395 & 0.370 & 0.105 \\
& Longan & 0.845 & 0.127 & $0.006^{*}$ & $0.011^{*}$ & 0.195 & $0.001^{*}$ \\
& Rambutan & NA & $0.001^{*}$ & $0.001^{*}$ & $0.001^{*}$ & $0.001^{*}$ & $0.001^{*}$ \\
\hline
\end{tabular}

${ }^{*}$ Interaction is significant at 0.05 level.

and TFC of litchi, whereas interaction between treatments and fruit forms was not strong in antioxidant assay.

\subsubsection{Effects of UV-C Treatment and Refrigeration on Longan.} Changes in $L$-ascorbic acid, TPC, TFC, DPPH free radical scavenging capacity, FRAP, and ABTS free radical scavenging capacity in whole longan fruit are illustrated in Figure 3(b). For each parameter, different subscripts denoted the existence of significant difference. Based on the comparison between fruits in control group $(\mathrm{N})$ and fruits only undergoing refrigeration (A1), cold storage does not significantly affect TPC and antioxidant capacity, but it was associated with the decrease of $L$-ascorbic acid and TFC. When UV-C light was applied as well (Groups B and C), all tested variables showed significant reduction in contrast with UV-negative groups. Additionally, $L$-ascorbic acid content in longans that experienced UV-C irradiation before storage was lower than its counterpart exposed to UV-C light after storage.
3.2.4. Effects of Dehulling and Destoning on Longan's Antioxidant Profile. Levels of $L$-ascorbic acid, TPC, TFC, DPPH free radical scavenging capacity, FRAP, and ABTS free radical scavenging capacity in longans with different fruit forms (whole, dehulled, and destoned) are illustrated in Table 2. Dehulling and destoning were both associated with diminishing nutritional levels in solely refrigerated longans (Group A), where the effect of dehulling was weaker in changes of $L$ ascorbic acid and ABTS free radical scavenging capacity, but stronger in reduction of other parameters. In group undergoing UV irradiation after refrigeration, destoned longans were found with higher level of TPC, TFC, FRAP, and DPPH free radical and ABTS free radical scavenging capacities than the counterparts in whole longan fruit and dehulled longans. Although values of above parameters in destoned fruit were slightly lower than in control group $\mathrm{N}$, removing core stone could help to reduce those antioxidant degradations. The similar tendency was observed in group refrigerated after UV-C 
treatment as well. While UV-C treated longan fruits did not show any retention of $L$-ascorbic acid, its loss was exacerbated in the peeled and destoned fruits. Two-way ANOVA (Table 3) indicated interaction between treatments and fruit forms was not significant in phytochemicals of longan, except TPC and DPPH free radical and ABTS free radical scavenging capacities.

\subsubsection{Effects of UV-C Treatment and Refrigeration on Rambu-} tan. Changes of TPC, TFC, DPPH free radical scavenging capacity, FRAP, and ABTS free radical scavenging capacity in whole rambutan fruit are illustrated in Figure 3(c). Compared with control group, refrigeration enriched TPC, FRAP, and ABTS free radical scavenging capacity but reduced values of TFC and DPPH scavenging capacity. Additionally, fruits which were pretreated by ultraviolet (Groups $\mathrm{B} 1$ and $\mathrm{C1}$ ), compared with control group, had lower phenolic contents. Levels of antioxidants were not significantly affected by the treatment order, except that rambutans irradiated by UV-C light before 24-hour storage performed higher DPPH scavenging rate.

3.2.6. Effects of Dehulling and Destoning on Rambutan's Antioxidant Profile. Levels of $L$-ascorbic acid, TPC, TFC, DPPH free radical scavenging capacity, FRAP, and ABTS free radical scavenging capacity in rambutan with different fruit forms (whole, dehulled, and destoned) are illustrated in Table 2. In the group of refrigeration, removing hull and core stone of rambutan were both associated with the decrease of phytochemical levels during refrigeration. However, for fruits treated by ultraviolet light, though phytochemical levels of TPC, TFC, FRAP, and DPPH free radical and ABTS free radical scavenging capacities diminished in whole fruit compared with in control, dehulling contributed to retention of above antioxidant parameters. TPC, FRAP, and ABTS free radical scavenging capacity in dehulled rambutans even rise. However, results indicated that if internal stones were removed from rambutan, levels of all examined phytochemicals lost more sharply. According to two-way ANOVA (Table 3), significant interactions between fruit forms and treatments were shown in all tested parameters of rambutan.

\section{Discussions}

According to Mercier et al. [35], low dose of UV-C exposure is not enough to kill microbes; therefore, the shelf-life extending effect of UV-C light is mainly attributed to the synthesis of antimicrobial phytoalexin. UV light exposure can be applied to fruits postharvest processing, which can extend 2-to-3-day selling time and thus reduce economic loss. Additionally, it was reported that UV irradiation can be potent when fruits were sprayed with chemicals, like $\mathrm{ClO}_{2}$ and fumaric acid [36], or when fruits were irradiated in ozone atmosphere, which can achieve 6-log microbial reduction [37]. It should be noticed that cold storage can cause negative effect on rambutan quality: under $7^{\circ} \mathrm{C}$, rambutan would suffer from chilling injury [38]. As rambutan spintern are dense with stomachs, moisture in spinterns can escape rapidly under $7^{\circ} \mathrm{C}$ and anthocyanin can be converted to its colorless form, turning to maroon [39], which might impair consumer acceptance. In addition, the elevation of membrane permeability can lead to physiological dysfunction [40]. Therefore, refrigeration is not applicable to rambutan.

The significant linear relationship between TPC and antioxidant capacities indicated that phenolic compounds contribute to a majority of antioxidant phytochemicals, which agreed with viewpoint reported in previous literatures [26, $41,42]$. Strong relationship among assays of FRAP and DPPH free radical and ABTS free radical scavenging capacities can be attributed to the same mechanism underlying behind different chemical reactions: electron transfer [42]. Clarke et al. [41] indicated that conducting two or more assays to estimate antioxidant capacity seemed to be redundant considering high correlation coefficients. To improve this study, instead of spending too much effort on antioxidant capacities, malondialdehyde (MDA), the product of membrane lipid oxidation, can be taken into consideration for understanding whether treatments could suppress membrane structural deterioration [10]. The weak relationship between $L$-ascorbic acid and some other parameters seemed to be contradictory with the common sense that $L$-ascorbic acid is an important antioxidant. Possible reason was that $L$-ascorbic acid contributes little in scavenging capacity which was largely attributable to phenolic compounds. Sricharoen et al. [43] examined antioxidant capacity of tomato extract and found that radical scavenging ability of $L$-ascorbic acid was relatively low, inferior to polyphenols and flavonoids. Moreover, UV irradiation was associated with $L$-ascorbic acid degradation [44], but considering phenolic compounds are generally more stable, the overall changing trend of antioxidant capacity should be positively related with total phenolic contents.

Based on results, litchis which were only refrigerated had higher level of TPC and TFC as well as antioxidant capacity than control group. Enrichment of phytochemical was also observed in TPC, FRAP, and ABTS free radical scavenging capacities of rambutan. The similar phenomenon was previously reported by Kevers at al. [45], finding an increase of antioxidants in leek and asparagus after the first day in cold environment; Piljac-Žegarac et al. [46] also reported elevations of phenolic content and DPPH free radical scavenging capacity in a variety of berries in the first $48 \mathrm{~h}$ of refrigerated storage, though phenolic content started to drop afterward. Sanchez-Ballesta et al. [47] observed the increase of PAL and CHS transcripts and elevation of anthocyanin content in cold-stored grape; however, it is still unclear whether the cold environment activates the antioxidant defense in grapes or the low temperatures maintain the levels of antioxidants. After being harvested from farm, litchis can be recommended to be stored in cold environment to minimize textural change and meanwhile to enhance phytochemical values. However, on the contrary, in terms of longan, refrigeration caused dramatic decrease of $L$-ascorbic acid and TFC. Degradation was also shown in TFC of rambutan. Similar previous finding was observed on citrus juice [48]. Castro-López et al. [49] also found a slight degradation of $L$-ascorbic acid in eight fruits during storage and attributed the reason to heat- and lightsensitive property of $L$-ascorbic acid. The disparities that 
different fruits responded differently under refrigeration can be related to postharvest metabolic rate: the original content could be oxidized and depleted if low metabolic rate cannot serve the adequate synthesis after stress response.

When ultraviolet was applied, result showed that TPC, TFC, and antioxidant capacity of litchi increased further, showing positive effects on varied phytochemicals. Likewise, Luthria et al. [19] observed the raise of phenolic content in tomato after UV exposure, especially caffeic acid, which was enriched to approximately $120 \%$ of its original level. Possible mechanism has been pinpointed by self-defense pattern of plant: Favory et al. [18] pointed out that UV radiation had triggered signaling pathway of COP1 and UVR8 photoperception protein to produce accumulation of anti-UV molecules, like tannins and flavonoids. Additionally, taking the order of treatments into consideration, litchi undergoing UV irradiation before storage contained higher level of TPC and DPPH free radical scavenging capacity, which indicated possible underlying accumulation pattern: UV treatment stimulates DNA expression, and time is needed to synthesize phytochemicals.

However, UV did not enrich phytochemicals levels in longan and rambutan; on the contrary, it caused diminution for all test parameters. Cote et al. [50] reported that strawberry fruit treated by high-intensity UV-C light $\left(4 \mathrm{~kJ} \mathrm{~m}^{-2}\right.$, $33 \mathrm{~W} \mathrm{~m}^{-2}$ ) showed a reduction in antioxidant capacity compared with control group. The possible reasons for the degradation could be attributable to the dose applied on longan and rambutan, though it is the same as the one applied on litchi, exceeding hormetic dose. Hormesis phenomenon is known as beneficial responses appear with low dose agent (hormetic dose) applied but harmful effect could be triggered by excessive amount [51, 52]. Although UV-C light gives benefits to fruit due to the stimulation of phytoalexin and phenolic compounds, it can also be harmful to plant cells [53]. Previous study indicated that ultraviolet could have adverse effect on plant tissues by altering epidermal cells' water permeability [54]. Besides gene of microbes, UV light has similar DNA damage on fruit, inducing pyrimidine dimers, which consequently lead to inhibition of production of secondary metabolites production. Contradictory with results of litchi, longan undergoing UV-C irradiation before refrigeration had lower level of $L$-ascorbic acid and FRAP, which could be explained as follows: due to hormesis effect, DNA of mesocarp cells in longan was impaired, and gene segments coding secondary metabolites were affected, which lead to suppression of phytochemical synthesis in the next storing day. Moreover, ultraviolet light was associated with the generation of free radicals in plant tissue [55], which can consequently neutralize antioxidants. Both inhibition of phytochemical synthesis and oxidation of phytochemicals contributed to the overall reduction of antioxidants.

So far, no research was conducted in study of how dehulling and destoning affect nutritional change induced by UV light, leading to insufficient previous research as references. In terms of litchi, removing external hull and removing core stone out both impede elevation of examined content induced by UV light, especially $L$-ascorbic acid, TPC, and TFC but did not affect litchis which were only refrigerated.
A possible reason was that bare pulp was exposed to the same dose of ultraviolet, which exceeded beneficial range and resulted into hormesis. The result of two-way ANOVA strengthened the interaction of fruit forms and UV treatment. However, it should be noticed that the effects of fruit forms on longan and rambutan's phytochemical levels did not corroborate with each other. For longans, compared with whole fruit, destoned longans generally retained nutritional levels, including TPC, TFC, and DPPH free radical and ABTS free radical scavenging capacities. This observation did not only appear in UV-treated groups, but also in UV-negative group, which means no matter what treatment was given, all destoned fruit can be subjected to nutritional lose. This was also corroborated by some large $p$ values $>0.05$ shown in Table 3. The reason could be hypothesized as that destoning triggered stronger defense mechanism of longan against wound-stress, enriching phytochemical levels. Nevertheless, according to data obtained from rambutan, fruits without hulls were observed having retaining effect on phytochemicals, and this effect did not appear in destoned rambutan. This phenomenon only arises in groups that experienced UV treatment, which indicated that the retention of nutrient was associated with ultraviolet irradiation; this was also supported by two-way ANOVA with small $p$ values $<0.05$ for all tested parameters of rambutan. The further losses of phytochemical level of dehulled rambutan and destoned longan could be associated with the exposure of mesocarp in air, thus boosting oxidation of antioxidant, because similar degradation was found in UV-negative groups. The effects of fruits forms on phytochemicals could be hypothesized as a multifactorial relationship of defense response against stress and contact surface with external atmosphere. The overall effect should be contingent on which factors take major accountability, which depends on fruit structure and pulp texture of varied fruit species.

A limitation of this study is that, instead of several different UV doses, only one UV-C dose was given to three different types of fruits. To figure out the most proper ultraviolet dose based on the hormesis phenomenon, further study might apply several different UV doses. Additionally, to understand whether phytochemical level change is an accumulative process or an immediate process, future study is suggested to perform molecular-level assays, like examination of mRNA coding phenylalanine ammonia lyase and photoperception protein, or to determine whether ultraviolet promotes free radical generation using electron paramagnetic resonance spin trapping.

\section{Conclusions}

In this study, UV-C light treatment $\left(3 \mathrm{~kJ} \mathrm{~m}^{-2}\right)$ and refrigeration (24-hour) both can inhibit fruit decay rate and had different effects on phytochemical profiles of litchi, longan, and rambutan: cold storage enriched litchi's nutritional value but mainly adversely affected antioxidant level of longan and rambutan; ultraviolet exposure $\left(3 \mathrm{~kJ} \mathrm{~m}^{-2}\right)$ led to the increases of phytochemical levels of litchi but exceeded hormetic dose of longan and rambutan and triggered adverse effect, causing degradation of antioxidants. Phytochemical levels in fruit 
irradiated by UV before refrigeration and fruit treated by UV after refrigeration were not consistent in some parameters, which were associated with the theory that UV is an elicitor stimulating defense response against stress, initiating accumulative change of phytochemical contents. Taking fruit forms into consideration, destoning retained antioxidants of longan whereas dehulling retained antioxidants of rambutan, but both removing hull and removing stone were associated with suppression of phytochemical accumulation in litchi after UV irradiation. The effects of treatments and fruit forms on antioxidant profile could be different from fruit to fruit.

\section{Abbreviations}

ABTS: 2,2'-Azino-bis(3-ethylbenzothiazoline-6sulphonic acid)

DCIP: 2,6-Dichlorophenolindophenol

DPPH: 2-Diphenyl-1-picrylhydrazyl

FE: $\quad$ Ferric equivalents

FRAP: Ferric reducing antioxidant power

TFC: Total flavonoid content

TPTZ: 2,4,6-Tri(2-pyridyl)-s-triazine

TPC: Total phenolic content

Trolox: 6-Hydroxy-2,5,7,8-tetramethylchroman-2carboxylic acid

UVR8: Ultraviolet response locus 8

COP1: Constitutively photomorphogenic 1.

\section{Conflicts of Interest}

The authors declare that they have no conflicts of interest.

\section{Acknowledgments}

This research was jointly supported by a research grant from the Beijing Normal University-Hong Kong Baptist University United International College (UICRG 201714) and one research grant supported by Zhuhai Higher Education Construction Project (Zhuhai Key Laboratory of Agricultural Product Quality and Food Safety).

\section{References}

[1] Global Strategy on Diet, Physical Activity and Health. [Online]., Available [Accessed, World Health Organization, [Accessed, 2017, http://www.who.int/dietphysicalactivity/fruit/en/.

[2] F. Shahidi and P. K. Wanasundara, "Phenolic antioxidants," Critical Reviews in Food Science and Nutrition, vol. 32, no. 1, pp. 67-103, 1992.

[3] A. C. Carr and B. Frei, "Toward a new recommended dietary allowance for vitamin $\mathrm{C}$ based on antioxidant and health effects in humans," American Journal of Clinical Nutrition, vol. 69, no. 6, pp. 1086-1107, 1999.

[4] C. Kaur and H. C. Kapoor, "Antioxidants in fruits and vegetablesthe millenniums health," in Proceedings of the Antioxidants in fruits and vegetables-the millennium's health, vol. 36, pp. 703$725,2001$.

[5] Y. M. Jiang and Y. B. Li, "Effects of low-temperature acclimation on browning of litchi fruit in relation to shelf life," The Journal of Horticultural Science \& Biotechnology, vol. 78, no. 4, pp. 437$440,2003$.

[6] X. Z. Zhou, Y. Chen, J. Y. Tang, S. F. Huang, and Y. Cao, "Loss estimation of litchi fruit due to pericarp browning," Chinese Journal of Tropical Crops, vol. 33, no. 8, pp. 1403-1408, 2012.

[7] C. Ribeiro, J. Canada, and B. Alvarenga, "Prospects of UV radiation for application in postharvest technology," Emirates Journal of Food and Agriculture, vol. 24, no. 6, pp. 586-597, 2012.

[8] D. Rico, A. B. Martín-Diana, J. M. Barat, and C. Barry-Ryan, "Extending and measuring the quality of fresh-cut fruit and vegetables: a review," Trends in Food Science \& Technology, vol. 18, no. 7, pp. 373-386, 2007.

[9] J. A. Guerrero-Beltrán and G. V. Barbosa-Cánovas, "Advantages and limitations on processing foods by UV light," Food Science and Technology International, vol. 10, no. 3, pp. 137-147, 2004.

[10] E. Ait Barka, S. Kalantari, J. Makhlouf, and J. Arul, "Effects of UV-C irradiation on lipid peroxidation markers during ripening of tomato (Lycopersicon esculentum L.) fruits," Australian Journal of Physiotherapy, vol. 27, no. 2, pp. 147-152, 2000.

[11] C. Stevens, V. A. Khan, J. Y. Lu et al., "Induced resistance of sweetpotato to Fusarium root rot by UV-C hormesis," Crop Protection, vol. 18, no. 7, pp. 463-470, 1999.

[12] M. T. Charles and J. Arul, "UV treatment of fresh fruits and vegetables for improved quality: A status report," Stewart Postharvest Review, vol. 3, no. 3, article no. 6, 2007.

[13] M. Erkan, S. Y. Wang, and C. Y. Wang, "Effect of UV treatment on antioxidant capacity, antioxidant enzyme activity and decay in strawberry fruit," Postharvest Biology and Technology, vol. 48, no. 2, pp. 163-171, 2008.

[14] P. Perkins-Veazie, J. K. Collins, and L. Howard, "Blueberry fruit response to postharvest application of ultraviolet radiation," Postharvest Biology and Technology, vol. 47, no. 3, pp. 280-285, 2008.

[15] J. Mercier, D. Roussel, M.-T. Charles, and J. Arul, "Systemic and local responses associated with UV- and pathogen-induced resistance to Botrytis cinerea in stored carrot," Journal of Phytopathology, vol. 90, no. 9, pp. 981-986, 2000.

[16] M. T. Charles, A. Goulet, and J. Arul, "Physiological basis of UV-C induced resistance to Botrytis cinerea in tomato fruit. IV. Biochemical modification of structural barriers," Postharvest Biology and Technology, vol. 47, no. 1, pp. 41-53, 2008.

[17] P. Cuadra, J. B. Harborne, and P. G. Waterman, "Increases in surface flavonols and photosynthetic pigments in Gnaphalium luteo-album in response to UV-B radiation," Phytochemistry, vol. 45, no. 7, pp. 1377-1383, 1997.

[18] J.-J. Favory, A. Stec, H. Gruber et al., "Interaction of COP1 and UVR8 regulates UV-B-induced photomorphogenesis and stress acclimation in Arabidopsis," EMBO Journal, vol. 28, no. 5, pp. 591-601, 2009.

[19] D. L. Luthria, S. Mukhopadhyay, and D. T. Krizek, "Content of total phenolics and phenolic acids in tomato (Lycopersicon esculentum Mill.) fruits as influenced by cultivar and solar UV radiation," Journal of Food Composition and Analysis, vol. 19, no. 8, pp. 771-777, 2006.

[20] A. Castagna, E. Chiavaro, C. Dall'Asta, M. Rinaldi, G. Galaverna, and A. Ranieri, "Effect of postharvest UV-B irradiation on nutraceutical quality and physical properties of tomato fruits," Food Chemistry, vol. 137, no. 1-4, pp. 151-158, 2013.

[21] M. Alothman, R. Bhat, and A. A. Karim, "UV radiation-induced changes of antioxidant capacity of fresh-cut tropical fruits," Innovative Food Science and Emerging Technologies, vol. 10, no. 4, pp. 512-516, 2009.

[22] P. Crupi, A. Pichierri, T. Basile, and D. Antonacci, "Postharvest stilbenes and flavonoids enrichment of table grape cv Redglobe 
(Vitis vinifera L.) as affected by interactive UV-C exposure and storage conditions," Food Chemistry, vol. 141, no. 2, pp. 802-808, 2013.

[23] D. Zagory, "Effects of post-processing handling and packaging on microbial populations," Postharvest Biology and Technology, vol. 15, no. 3, pp. 313-321, 1999.

[24] H. Crisosto and K. R. Day, "Stone fruit," in Crop Post-Harvest: Science and Technology, D. Ree, Farrell., G., and J. Orchard, Eds., pp. 212-225, Wiley-Blackwell, Hoboken, NJ, USA, 2012.

[25] National Standard of PRC, "Method for determination of dry matter and water content in fruit and vegetable product, p. 118$120,1988^{\prime \prime}$.

[26] B. J. Xu and S. K. C. Chang, "A comparative study on phenolic profiles and antioxidant activities of legumes as affected by extraction solvents," Journal of Food Science, vol. 72, no. 2, pp. S159-S166, 2007.

[27] C. Reiss, Measuring the amount of ascorbic acid in cabbage , Tested studies for laboratory teaching,.

[28] X. Huang, W. Cai, and B. Xu, "Kinetic changes of nutrients and antioxidant capacities of germinated soybean (glycine max 1.) and mung bean (vigna radiata 1.) with germination time," Food Chemistry, vol. 143, pp. 268-276, 2014.

[29] V. L. Singleton, R. Orthofer, and R. M. Lamuela-Raventós, "Analysis of total phenols and other oxidation substrates and antioxidants by means of folin-ciocalteu reagent," Methods in Enzymology, vol. 299, pp. 152-178, 1999.

[30] D. Heimler, P. Vignolini, M. G. Dini, and A. Romani, "Rapid tests to assess the antioxidant activity of Phaseolus vulgaris L. dry beans," Journal of Agricultural and Food Chemistry, vol. 53, no. 8, pp. 3053-3056, 2005.

[31] C. CHEN and C. HO, "Antioxidant properties of polyphenols pxtracted from green and black teas," Journal of Food Lipids, vol. 2, no. 1, pp. 35-46, 1995.

[32] I. F. F. Benzie and J. J. Strain, "The ferric reducing ability of plasma (FRAP) as a measure of 'antioxidant power': the FRAP assay," Analytical Biochemistry, vol. 239, no. 1, pp. 70-76, 1996.

[33] T. Islam, X. Yu, and B. Xu, "Phenolic profiles, antioxidant capacities and metal chelating ability of edible mushrooms commonly consumed in China," LWT- Food Science and Technology, vol. 72, pp. 423-431, 2016.

[34] X. Zeng, J. Yin, and H. Gao, "Effects of UV-C and CF-3 on quality of postharvest litchi," Food and Fermentation Industries, vol. 40, pp. 219-224, 2014.

[35] J. Mercier, M. Baka, B. Reddy, R. Corcuff, and J. Arul, "Shortwave ultraviolet irradiation for control of decay caused by Botrytis cinerea in bell pepper: Induced resistance and germicidal effects," Journal of the American Society for Horticultural Science, vol. 126, no. 1, pp. 128-133, 2001.

[36] M. V. Selma, A. Allende, F. López-Gálvez, M. A. Conesa, and M. I. Gil, "Disinfection potential of ozone, ultraviolet-C and their combination in wash water for the fresh-cut vegetable industry," Food Microbiology, vol. 25, no. 6, pp. 809-814, 2008.

[37] J. Y. Kim, H. J. Kim, G. O. Lim, S. A. Jang, and K. B. Song, “The effects of aqueous chlorine dioxide or fumaric acid treatment combined with UV-C on postharvest quality of 'Maehyang' strawberries," Postharvest Biology and Technology, vol. 56, no. 3, pp. 254-256, 2010.

[38] T. J. O’Hare, "Postharvest physiology and storage of rambutan," Postharvest Biology and Technology, vol. 6, no. 3-4, pp. 189-199, 1995.

[39] T. O'hare and S. Underhill, "Colour degradation of rambutan pericarp," Horticulture Postharverst Group Biennial Review, vol. 1994, p. 40, 1992.
[40] K. L. Parkin, A. Marangoni, R. L. Jackman, R. Y. Yada, and D. W. Stanley, "Chilling Injury. A Review of Possible Mechanisms," Journal of Food Biochemistry, vol. 13, no. 2, pp. 127-153, 1989.

[41] G. Clarke, K. Ting, C. Wiart, and J. Fry, "High Correlation of 2,2-diphenyl-1-picrylhydrazyl (DPPH) Radical Scavenging, Ferric Reducing Activity Potential and Total Phenolics Content Indicates Redundancy in Use of All Three Assays to Screen for Antioxidant Activity of Extracts of Plants from the Malaysian Rainforest," Antioxidants, vol. 2, no. 1, pp. 1-10, 2013.

[42] D. Huang, B. Ou, and R. L. Prior, "The chemistry behind antioxidant capacity assays," Journal of Agricultural and Food Chemistry, vol. 53, no. 6, pp. 1841-1856, 2005.

[43] P. Sricharoen, S. Techawongstein, D. Luthria, and S. Chanthai, "Standardization of DPPH, ABTS and FRAP assays with six reference compounds for estimating antioxidant capacity of the tomato extracts using an ultrasound assisted extraction," vol. 6, pp. 608-616, 2015.

[44] R. V. Tikekar, R. C. Anantheswaran, and L. F. LaBorde, "Ascorbic Acid Degradation in a Model Apple Juice System and in Apple Juice during Ultraviolet Processing and Storage," Journal of Food Science, vol. 76, no. 2, pp. 62-71, 2011.

[45] C. Kevers, M. Falkowski, J. Tabart, J.-O. Defraigne, J. Dommes, and J. Pincemail, "Evolution of antioxidant capacity during storage of selected fruits and vegetables," Journal of Agricultural and Food Chemistry, vol. 55, no. 21, pp. 8596-8603, 2007.

[46] J. Piljac-Žegarac, L. Valek, S. Martinez, and A. Belščak, "Fluctuations in the phenolic content and antioxidant capacity of dark fruit juices in refrigerated storage," Food Chemistry, vol. 113, no. 2, pp. 394-400, 2009.

[47] M. T. Sanchez-Ballesta, I. Romero, J. B. Jiménez et al., "Involvement of the phenylpropanoid pathway in the response of table grapes to low temperature and high CO2 levels," Postharvest Biology and Technology, vol. 46, no. 1, pp. 29-35, 2007.

[48] A. del Caro, A. Piga, V. Vacca, and M. Agabbio, "Changes of flavonoids, vitamin $\mathrm{C}$ and antioxidant capacity in minimally processed citrus segments and juices during storage," Food Chemistry, vol. 84, no. 1, pp. 99-105, 2004.

[49] C. Castro-López, E. J. Sánchez-Alejo, S. Saucedo-Pompa, R. Rojas, J. Aranda-Ruiz, and G. C. G. Martínez-Avila, "Fluctuations in phenolic content, ascorbic acid and total carotenoids and antioxidant activity of fruit beverages during storage," Heliyon, vol. 2, no. 9, Article ID e00152, 2016.

[50] S. Cote, L. Rodoni, E. Miceli, A. Concellón, P. M. Civello, and A. R. Vicente, "Effect of radiation intensity on the outcome of postharvest UV-C treatments," Postharvest Biology and Technology, vol. 83, pp. 83-89, 2013.

[51] J. Arul, J. Mercier, M.-T. Charles, M. Baka, and R. Maharaj, "Photochemical treatment for control of post-harvest diseases in horticultural crops," in Physical Control Methods in Plant Protection, pp. 146-161, Springer, 2001.

[52] E. J. Calabrese, M. E. McCarthy, and E. Kenyon, "The occurrence of chemically induced hormesis," Health Physics Journal, vol. 52, no. 5, pp. 531-541, 1987.

[53] L. A. Terry and D. C. Joyce, "Elicitors of induced disease resistance in postharvest horticultural crops: a brief review," Postharvest Biology and Technology, vol. 32, no. 1, pp. 1-13, 2004.

[54] I. Lichtscheidl-Schultz, "Effects of UV-C and UV-B on cytomorphology and water permeability of inner epidermal cells of Allium cepa," Physiologia Plantarum, vol. 63, no. 3, pp. 269-276, 1985.

[55] C. Sgherri, C. Scattino, C. Pinzino, P. Tonutti, and A. M. Ranieri, "Ultraviolet-B radiation applied to detached peach fruit: A study of free radical generation by EPR spin trapping," Plant Physiology and Biochemistry, vol. 96, pp. 124-131, 2015. 

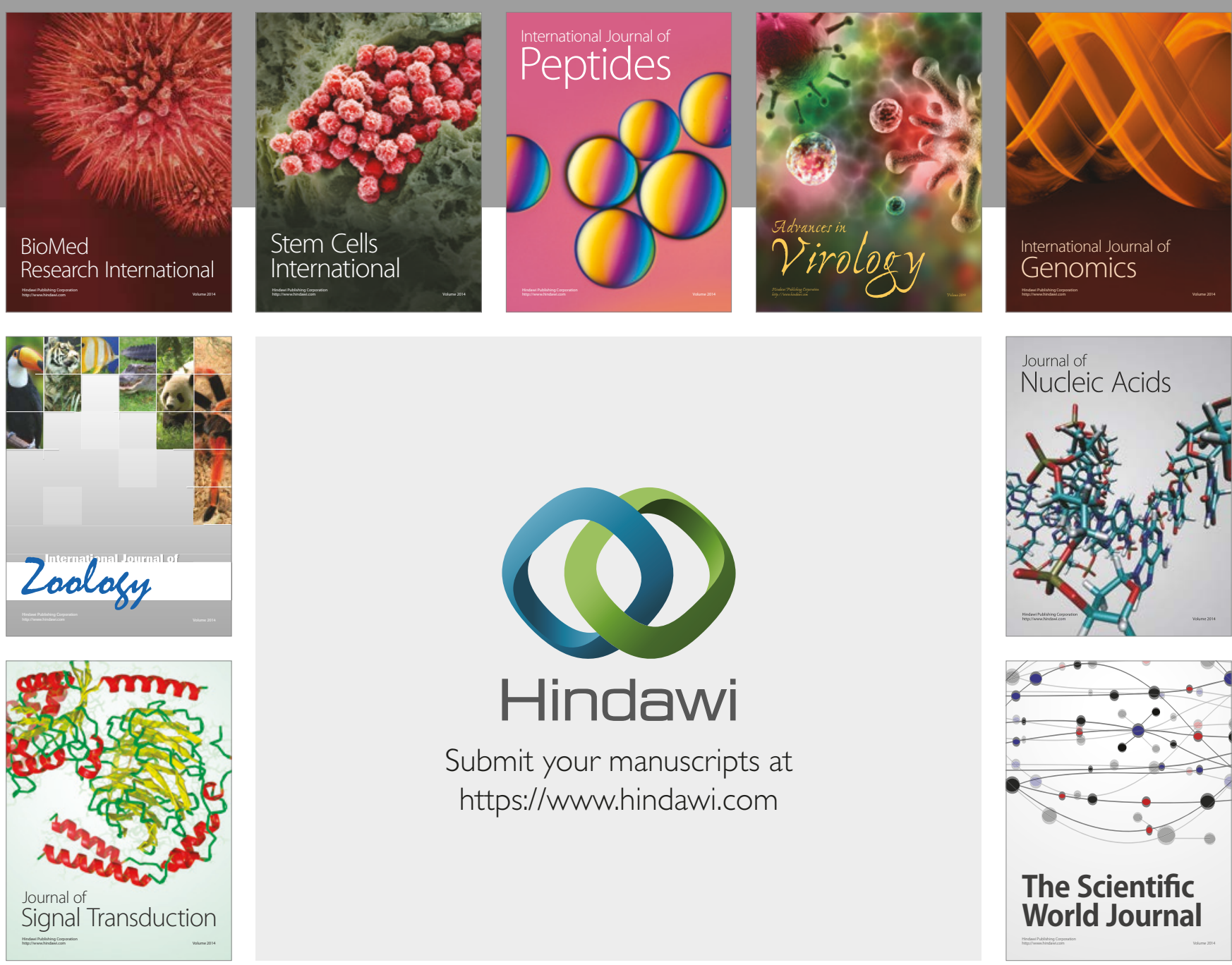

Submit your manuscripts at

https://www.hindawi.com
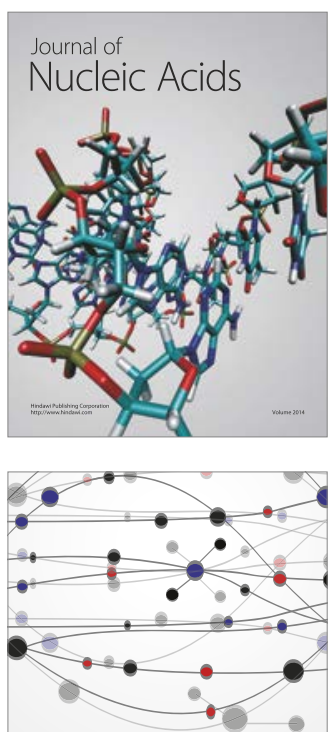

The Scientific World Journal

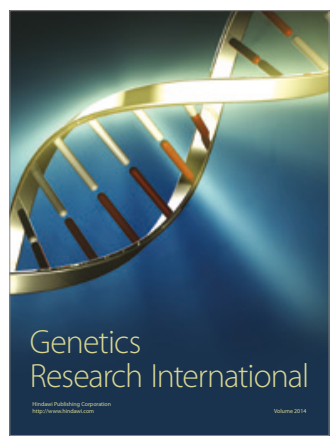

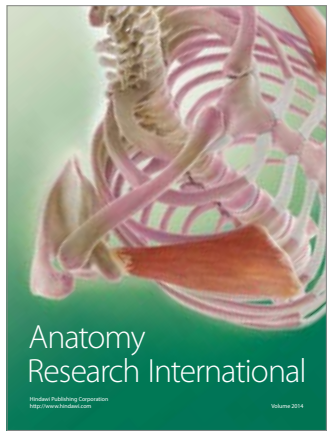

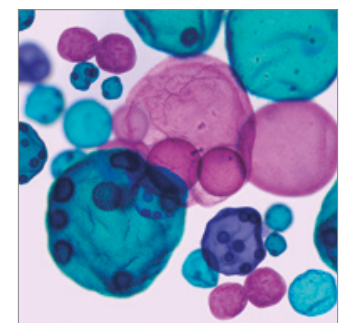

International Journal of Microbiology
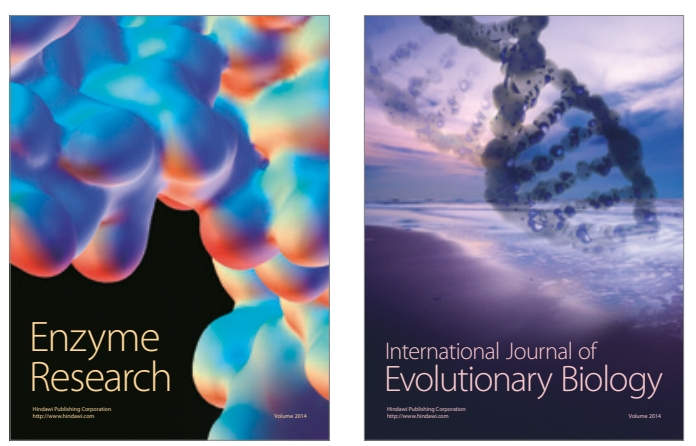
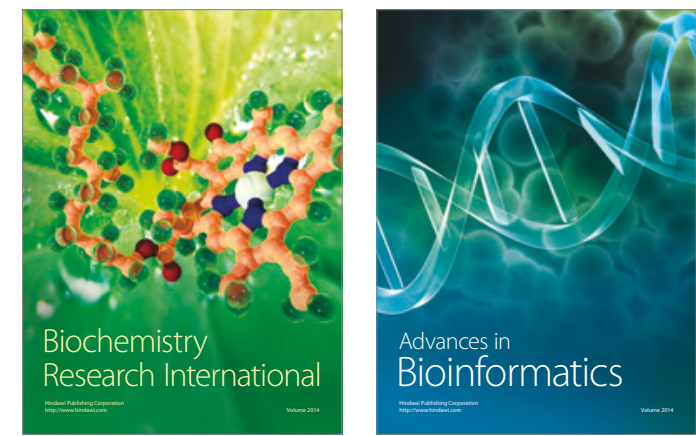

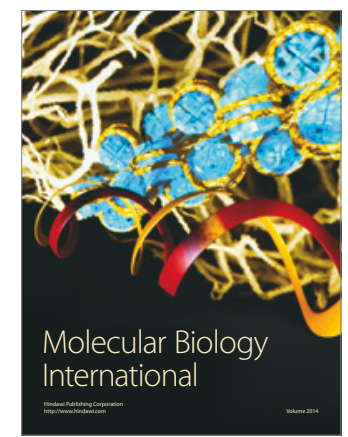

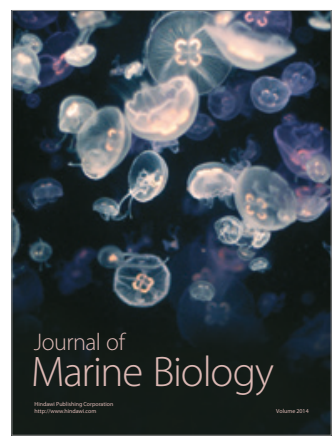

